DOI: 10.17148/IARJSET.2021.8956

\title{
AutoCAD and Computer
}

\section{Prem Chandra}

JECRC University, Jaipur, Rajasthan, India

\begin{abstract}
Earlier manual drafting \& design was carried out by using tools like scales, Compasses, protectors, T-square, Mini Drafter etc. For engineers and architects, it was time taking and not fit for repetitive design. After evolution of latest technologies and innovation in high end computers with development of software, designing \& drafting becomes easier, accurate and faster. Manual drafting is now replaced by latest CAD Tools used with computers. One of the software applications for Computer Aided Design (CAD) \& drafting is AutoCAD. It is very useful not only with engineering industry but many other industries too.
\end{abstract}

Keywords: Computer Aided Design, AutoCAD software, drafting tool, Personal Computer, modelling, analysis.

\section{INTRODUCTION}

In the old days manual drafting method was used by architects and engineers. It was time taking process due to use of pen and papers. Nowadays industries are using Computer-Aided Design/Drafting systems with help of computers to design, drafting, modelling and even analysis too. These Computer Aided Design \& Drafting tools replaced the manual drafting method. There are various software for design purpose in the market, but one of the most user friendly commercially CAD software is AutoCAD.

\section{WHAT IS AUTOCAD}

The word AutoCAD is made up of two words "Auto" (Logo of the Company) and "CAD" (Computer Aided Design /Drafting).It was first developed by USA based company Autodesk founded by Mr John Walker and launched in December 1982.AutoCAD application is designed to run on mini computers and personal computers. This CAD tool allowed the users to to create detailed technical drawings and was affordable to many smaller design, engineering and architecture companies. It was launched in 1988 in India. AutoCAD is a 2D and 3D modelling software which is used with help of Personal Computers. The first version of AutoCAD was R1 after that R2, R3,.... and upto R14.In year 2000, Autodesk launched a version of AutoCAD 2000 after that 2001, 2002.... and so on. The latest version is 2022 , launched in March 2021.

\section{LITERATURE REVIEW}

"AutoCAD allows creation not just for normal drawing. Logically connected fragments can be placed on the allocated layers or grouped in compound objects. And we consider them as a whole entity. AutoCAD "remembers" position, size, color of the constructed objects and writes down this data in an internal database for their subsequent search, analysis, and processing. AutoCAD can function with a wide range of personal computers and graphic workstations under control of various operating systems [1], [2]."

"AutoCAD is a powerful tool for automating graphical work based on personal computers. It gives the user possibilities which earlier could be realized only on big and expensive computing systems: any drawing that was drawn manually can be constructed with AutoCAD now. AutoCAD is capable to perform almost any kinds of graphic works [3], [4]."

\section{PRODUCTS AND ITS APPLICATIONS}

AutoCAD products are in the form of collections and are as follows:

(a). Architecture, Engineering \& Construction Collection (AEC): It provides designers, engineers and contractors a set of BIM and CAD tools supported by a cloud-based common data environment that facilitates project delivery from early-stage design through to construction.

(b). Product Design and manufacturing collection (PDMC): It The collection is a powerful set of applications that provides extended capabilities to Inventor and AutoCAD for engineers who design complex and customised products, equipment and systems. It extends Inventor with add-ins for tolerance analysis, simulation and production layout. It use connected products for 2D drafting, large-scale design review and visualization \&Connect to Fusion 360 to access nextgeneration capabilities and collaboration 


\section{International Advanced Research Journal in Science, Engineering and Technology}

Vol. 8, Issue 9, September 2021

DOI: $10.17148 /$ IARJSET.2021.8956

(c). Media and Entertainment Collection: It includes all of the tools you need to build a powerful and scalable 3D animation pipeline for complex simulations, effects and rendering. It provides from detailed battle sequences to hyper realistic creatures, render your toughest projects with Arnold. It create complex effects including explosions, fire, sand and snow with Bi frost for Maya. It empower artists with a choice of tools to produce beautiful, film-quality work every time. Various top products are mentioned in table-1.

\section{Table.1. Top AutoCAD Products}

\begin{tabular}{|l|l|l|}
\hline S No & Product Name & Uses \\
\hline 1 & AutoCAD Architecture & Architectural drafting \\
\hline 2 & AutoCAD Civil 3D & Civil Engineering Design \& Documentation \\
\hline 3 & AutoCAD Electrical & Circuit Design and panel layout \\
\hline 4 & AutoCAD LT & Quick design Documentation \\
\hline 5 & AutoCAD MAP 3D & GIS and Mapping \\
\hline 6 & AutoCAD Mechanical & Mechanical Design and drafting \\
\hline 7 & AutoCAD MEP & Draft, design and documentation of building system \\
\hline 8 & AutoCAD P\&ID & Piping and Instrumentation diagram \\
\hline 9 & AutoCAD Plant 3D & Plant Layout design \\
\hline 10 & AutoCAD Raster Design & Raster Images, maps and aerial photos \\
\hline 11 & AutoCAD Structural Detailing & Structural detailing \\
\hline 12 & AutoCAD Utilities Design & Design overhead and underground structures \\
\hline
\end{tabular}

\section{WHAT CAN IT DO}

AutoCAD screen is shown in Fig.-2 and its application in graphics design is shown in Fig.-1.

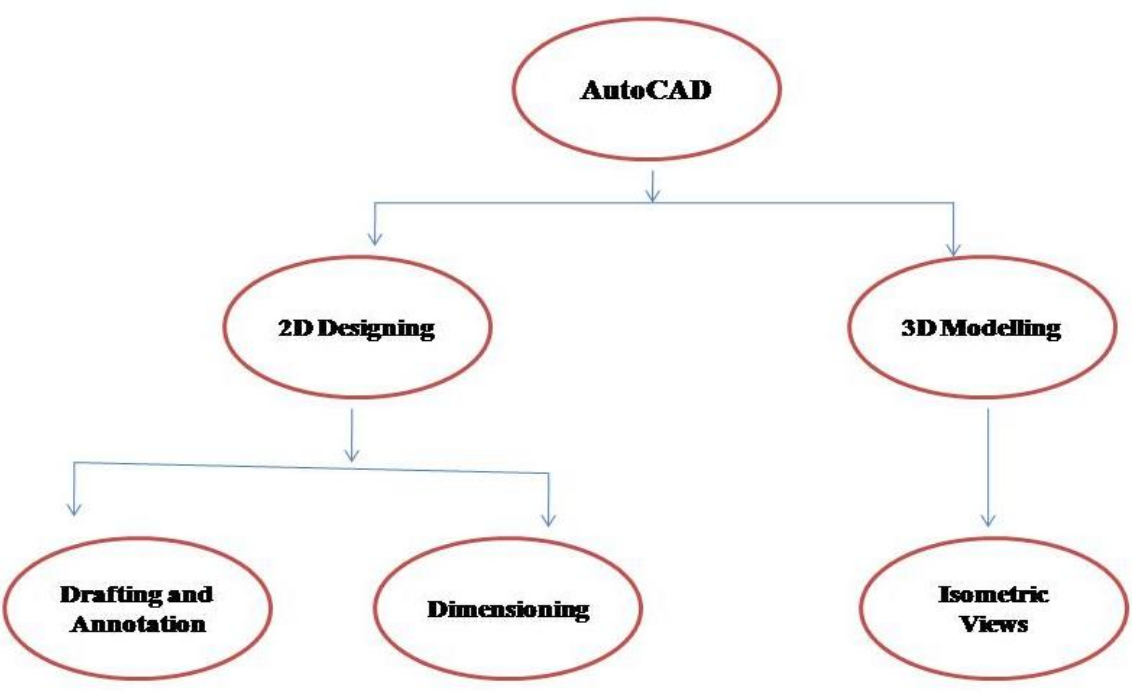

Fig.-1.Application of AutoCAD 
Vol. 8, Issue 9, September 2021

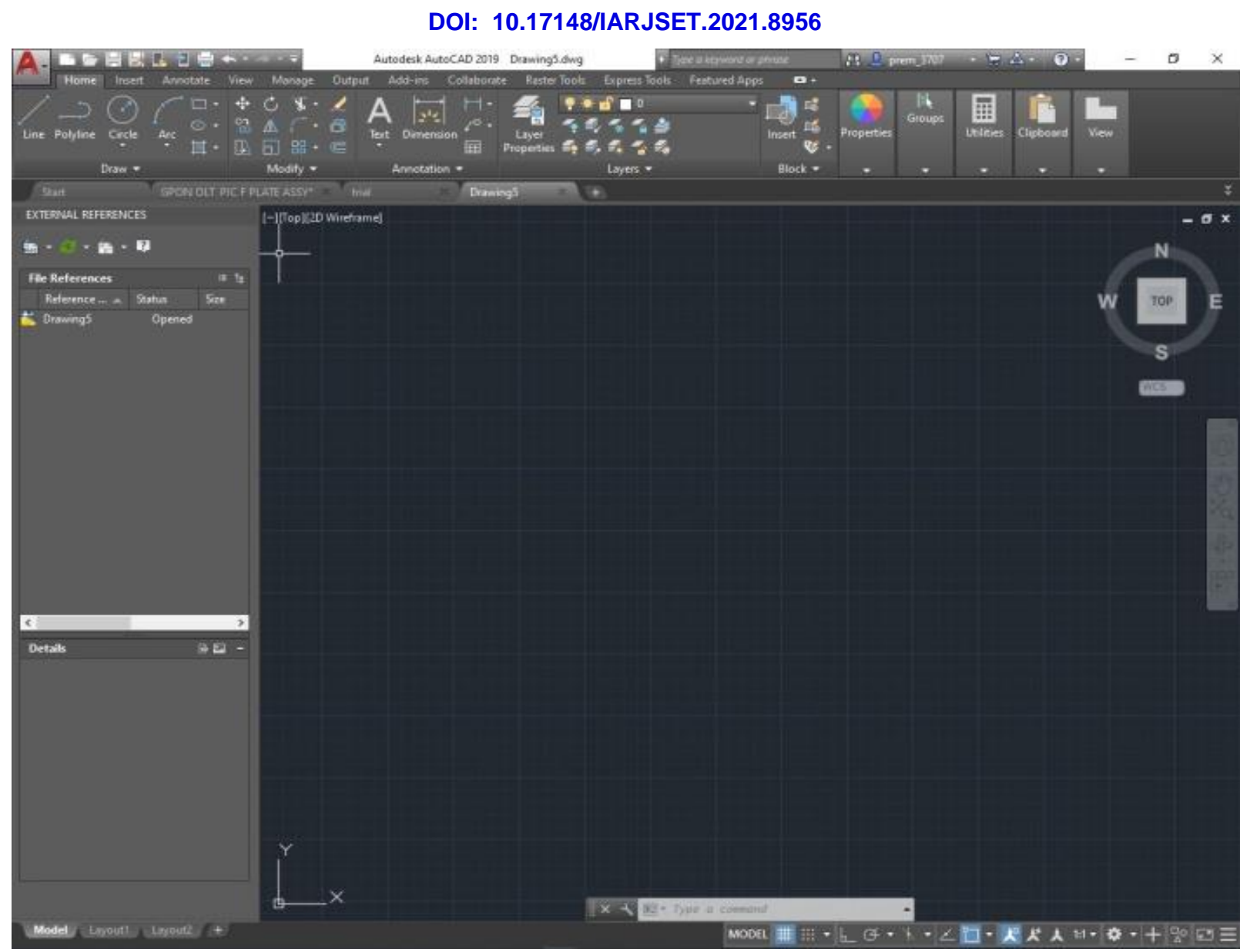

Fig.-1. AutoCAD Screen

\section{BENEFITS OF AUTOCAD}

It allows to draw and edit digital 2D and 3D designs more quickly and easily. The files can also be easily saved and stored on cloud to access anywhere and anytime by the user.

Following are the other major benefits:

1). Modification point of view: In this application major benefit is to easily edit, change and manipulations in the design by using computer.

2). Production point of view: In this we can create a reusable block library using window system to get easy access. For repetitive components we can use block library to increase the design efficiency and makes process faster.

3). Accuracy point of view: In this we can create more accurate design and even very small size of components to be designed.

4).Easy to prototype: Once the model is ready to use, we can feed it to 3D printer for rapid prototype

5). It improves productivity in drafting \& shorter preparation time required for drawing.

6).It reduced manpower requirements \&modifications in drawing are easier.

7).It is more efficient operation in drafting \& very low wastage in drawings.

8). It maintains very good accuracy of drawing \& easy in documentation.

\section{LIMITATION/DRAWBACK OF AUTOCAD}

As mentioned in above paragraph regarding benefits, but it has some limitations/drawback too. Which are as follows:

(1). As we know that this software have many modules so it requires more space for installation and storage.

(2). Large amount of memory required for better viewing of the graphics.

(3). Huge investment for the software purchase. 


\section{International Advanced Research Journal in Science, Engineering and Technology}

Vol. 8, Issue 9, September 2021

DOI: $10.17148 /$ IARJSET.2021.8956

\section{CONCLUSIONS}

AutoCAD is very power full tool for CAD purpose in engineering drawing and easy to use. It is useful in $2 \mathrm{D} \& 3 \mathrm{D}$ both type of drawing. It can save the time for project. In latest version some analysis also is done.

\section{REFERENCES}

[1] Abbasov, I. B. (2007). Create computer drawings in AutoCAD 2007/2008. Moscow: DMK Press.

[2] Ozkaya, S. I. (2018). FRACOR-software toolbox for deterministic mapping of fracture corridors in oil fields on AutoCAD platform. Computers \& Geosciences, 112, 9-22.

[3] Nikulin, E. A. (2005).Komp'yuternaya geometriya i algoritmy mashinnoi grafiki (Computer Geometry and Algorithms of Computer Graphics), St. Petersburg: BKhV Peterburg..

[4] Patpatiya, Parth and Sharma, Shailly and Bhatnagar, Varun and Tomar, Jyoti and Shalu, JyotiKumari, Approaches for Concising AutoCAD Files (September 2, 2019). Proceedings of International Conference on Advancements in Computing \& Management (ICACM) 2019.

[5] Mohd Rafeeq Ur Rahman, Mohammed Iqbal Khatib, P. Seema Rani, Shahin Shaikh, Gunashekar.G (2019). Effect of Computer Aided Drafting on Manual Drafting Skills. International Journal of Innovative Technology and Exploring Engineering (IJITEE) ISSN: 2278-3075, Volume8 Issue-11.

[6] Runmei Zhang1 and YehuanGu. (2017). Research on AutoCAD secondary development and function expansion based on VBA technology. 3rd International Conference on Advances in Energy, Environment and Chemical Engineering IOP Publishing IOP Conf. Series: Earth and Environmental Science 69 (2017).

[7] Alexey L. Khoroshko. (2020). The Research of the Possibilities and Application of the AutoCAD Software Package for Creating Electronic Versions of Textbooks for "Engineering and Computer Graphics". TEM Journal Volume 9, Issue 3, Pages 1141-1149, ISSN 2217-8309.

[8] https://www.autodesk.in

[9] Presentation on AutoCAD by Mr.Vaibhavgautam

[10] Presentation:AutoCADSoftware by Mr.Waqas Ali, Source: www.academia.edu.

[11] J. A. JIMOH, (2019), COMPARATIVE EFFECTS OF 2D AND 3D METHODS OF GRAPHICS IN AUTOCAD ON INTEREST OF NATIONAL DIPLOMA STUDENTS IN ENGINEERING GRAPHICS IN SOUTH-WEST NIGERIA, International Journal of Educational Research Vol. 6, No 1, 2019.

[12] Vinod C; Menaka D. "Computer Aided Detection of Nodule from Computed Tomography Images of Lung". International Research Journal on Advanced Science Hub, 3, Special Issue ICARD-2021 3S, 2021, 96-100. doi: 10.47392/irjash.2021.073 